\title{
FBLN3 inhibits the invasion and metastasis of colorectal cancer through the AKT/mTOR pathway
}

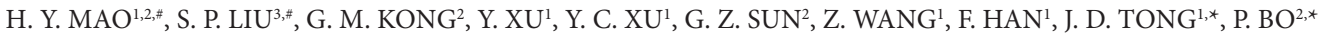 \\ ${ }^{1}$ Department of Oncology, The Affiliated Hospital of Yangzhou University, Yangzhou University, Yangzhou, China; ${ }^{2}$ Medical College of Yangzhou \\ University, Yangzhou University, Yangzhou, China; ${ }^{3}$ Yangzhou Hospital of Traditional Chinese Medicine Affiliated to Nanjing University of \\ Chinese Medicine, Nanjing University of Chinese Medicine, Yangzhou, China
}

*Correspondence: tongjiandong@csco.ac.cn,boping@yzu.edu.cn

${ }^{*}$ Contributed equally to this work.

Received May 21, 2017 / Accepted July 22, 2017

\begin{abstract}
Fibulin-3 (FBLN3) levels vary among different types of cancers. We found that fibulin-3 was downregulated in colorectal cancer (CRC) cells, particularly in the SW480 cell line. However, transfecting SW480 cells with a lentivirus overexpressing fibulin-3 RNA inhibited proliferation, induced G1/S arrest, and promoted apoptosis. Fibulin-3 overexpression also suppressed CRC invasion and metastasis. These effects were regulated through the AKT/mTOR signaling pathway.
\end{abstract}

Key words: fibulin-3, invasion, metastasis, colorectal cancer, AKT/mTOR pathway

Colorectal cancer (CRC) is a common disease with high morbidity and mortality rates globally, particularly in China. $\mathrm{CRC}$ is a malignancy with the third-highest morbidity and is the second-highest cause of cancer-related death worldwide $[1,2]$.

Based on cancer statistics from 2015, CRC is also associated with third-highest morbidity and the fifth-highest death rate among all malignancies in China [2]. Despite earlier diagnosis thanks to advanced diagnostic approaches, overall survival remains poor. Moreover, many patients lose their eligibility for surgery due to distant metastases. It has been reported that marital status [3] and social integration [4] are related to a poor prognosis. In recent years, researchers have investigated molecular and biological factors to prevent invasion and metastasis of CRC to prolong patient survival, and studying these processes is vital for predicting the course of the disease [5].

Fibulins (FBLNs) comprise a family of secreted glycoproteins that are characterized by epidermal growth factor (EGF)-like domain repeats [6]. Fibulin-3 (FBLN3), encoded by the EGF-containing fibulin-like extracellular matrix protein 1 (EFEMP1) gene, is a member of the fibulin family that has been newly recognized as an extracellular matrix protein. It is also a unique C-terminal fibulin-like molecule. FBLN3 was recently confirmed to act as a tumor suppressor or activator in many cancers. It also plays an important role in regulating cell growth. FBLN3 is closely associated with
CRC development, though the mechanism remains unclear. In this study, we aimed to elucidate the exact mechanisms of FBLN3 in CRC.

\section{Materials and methods}

Reagents. F-12K, RMPI-1640 medium and fetal bovine serum (FBS) were purchased from Gibco (Thermo Fisher Scientific, China) and stored at $4{ }^{\circ} \mathrm{C}$ until use. FBLN3 lentivirus was obtained from Shanghai Genechem Co., Ltd (Shanghai, China) and stored at $-20^{\circ} \mathrm{C}$. Trizol, SYBR Green and BCA protein kits were all acquired from Thermo Fisher Scientific. Annexin V Apoptosis Detection Kit APC was obtained from eBioscience, the reverse transcription kit was obtained from Fermentas. Antibodies against FBLN3, AKT, p-AKT, mTOR, p-mTOR, cyclin D1, MMP-2, MMP-9, CKI, Bcl-2, Bax and GAPDH were purchased from Abcam (all Shanghai, China). Matrigel was obtained from BD Biosciences (New Jersey, USA). Other reagents used in the experiments were purchased from different chemical companies.

Cell culture and infection. The human normal colorectal cell line FHC and CRC cell lines LOVO, SW620, SW1116, SW480, and HCT116 were purchased from the Cell Bank of the Chinese Academy of Sciences, Shanghai Institute of Cell Biology (Shanghai, China). All CRC cells were cultured in RPMI-1640 or F-12K medium containing $10 \%$ FBS and $1 \%$ penicillin and streptomycin in a humidified incubator 
at $37^{\circ} \mathrm{C}$ with $5 \% \mathrm{CO}_{2}$. Selected SW480 cells were seeded in six-well plates at $1.5 \times 10^{5}$ cells per well for $24 \mathrm{~h}$ and after that the cells were transfected with $10 \mu$ l of lentivirus overexpressing FBLN3 RNA or a negative control. The sequences were as follows: FBLN3 - sense, 5'-GCGAATTCATGTTGAAAGCCCTTTTCCTAAC (EcoR I), and antisense, 5' - CGGGATCC CTA A A A TGA A A ATG GCCCCAC (BamH I); NC - sense, 5'-UUCUCCGAACGUGUCACGUTT-3', and antisense, 5'-ACGUGACACGUUCGGAGAATT-3'. The underlined sequences are restriction enzyme sites. Next, $2 \mathrm{ml}$ of medium was added to each well and experiments were performed after $48 \mathrm{~h}$.

Cell proliferation assay. To detect cell proliferation, MTT assays were performed according to the manufacturer's instructions. SW480 cells were seeded in 96-well plates at $3 \times 10^{3}$ cells per well. After transfection for $0 \mathrm{~h}, 24 \mathrm{~h}, 48 \mathrm{~h}$ and $72 \mathrm{~h}, 20 \mu \mathrm{l}$ of MTT $(5 \mathrm{mg} / \mathrm{ml})$ was added to each well and incubated for $4 \mathrm{~h} ; 150 \mu \mathrm{l}$ of DMSO was then added to each well. OD values were measured at $490 \mathrm{~nm}$ absorbance using an ELISA microreader.

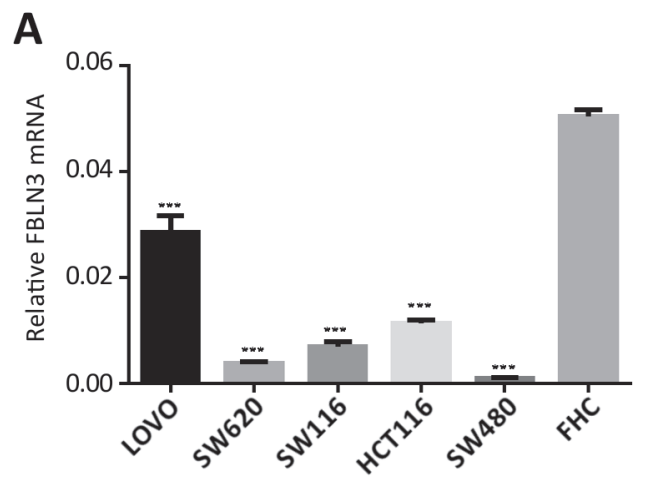

B

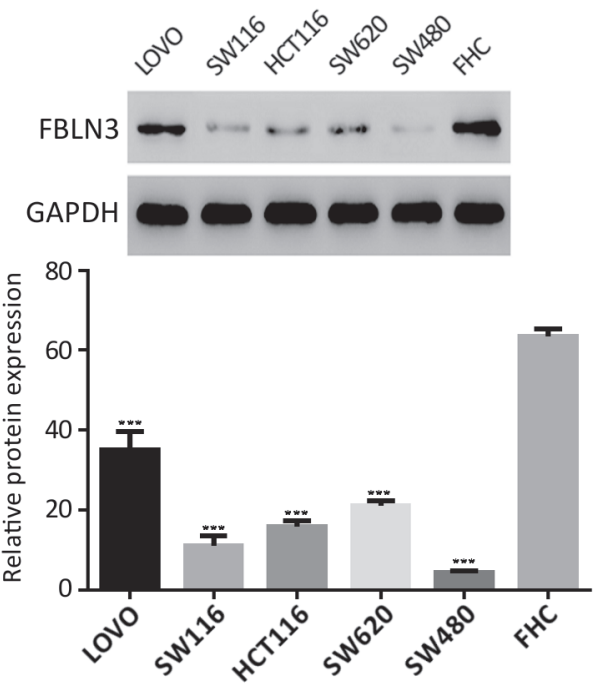

Figure 1. A) FBLN3 mRNA expression in five colorectal cancer cell lines, as analyzed by RT-PCR. B) FBLN3 protein expression in the five colorectal cancer cell lines, as analyzed by western blotting.
Flow cytometric analysis. Flow cytometry was applied to measure apoptosis and cell cycle. Briefly, after $48 \mathrm{~h}$ transfection, cells were collected and re-suspended. Apoptosis and cell cycle kits were used according to the manufacturer's instructions, and the cells were analyzed by flow cytometry as soon as possible.

Invasion and migration assays. Transwell inserts were used to assess migration and invasion abilities. For the invasion assays, after $48 \mathrm{~h}$ transfection log-phase cells were trypsinized, washed with serum-free medium and re-suspended at $4 \times 10^{5}$ cells $/ \mathrm{ml}$ in medium containing $1 \%$ serum. The cells were then seeded in Boyden chambers $(8 \mu \mathrm{m}$ pore size). Matrigel was not used in cell migration assays. Filters were inserted into the lower chamber of a 24-well transwell chamber apparatus (Costar, Cambridge, MA, USA) with medium containing $10 \% \mathrm{FBS}(700 \mu \mathrm{l})$ and incubated for $24 \mathrm{~h}$. Afterwards, the material in each well was dyed with a crystal violet solution for 30 minutes and cells on the top filter were carefully wiped off with a cotton swab. For each filter, the number of migratory or invasive cells was calculated under a fluorescence microscope.

Real-time polymerase chain reaction (RT-PCR). Total RNA was extracted with Trizol (Invitrogen, CA, USA), and RT-PCR was carried out using a reverse transcription reagent kit (Thermo, USA) and SYBR Green PCR reagent (Fermentas) according to the manufacturer's instructions. PCR amplification of FBLN3 and GAPDH was performed for $15 \mathrm{~s}$ at $95^{\circ} \mathrm{C}$ and $45 \mathrm{~s}$ at $60^{\circ} \mathrm{C}$, followed by 40 cycles for 10 minutes and extension at $60^{\circ} \mathrm{C}$ for 1 minute. The results were analyzed with ABI 7300 SDS software (Applied Biosystems, Foster City, CA, USA). The specific primer sequences for each gene were as follows: FBLN3 - forward, 5'ATGCAGAACCTCAAGCTACC-3', and reverse, 5'-GAAGCCGCCATGATAATTCC-3'; GAPDH - forward, 5'-CACCCACTCCTCCACCTTTG-3', and reverse, 5'-CCACCACCCTGTTGCTGTAG-3'.

Western blot assay. SW480 cells were lysed in cold lysis buffer with PMSF and protease and phosphatase inhibitors. Proteins were extracted according to the reagent instructions and denatured with loading buffer for five minutes at $95^{\circ} \mathrm{C}$. Total protein concentrations were measured by BCA assay. Equal amounts of proteins were loaded, separated by $10 \%$ sodium dodecyl sulfate-polyacrylamide gel electrophoresis (SDS-PAGE) and transferred onto polyvinylidene fluoride (PVDF) membranes by electrophoresis. Each membrane was incubated with different antibodies (FBLN3 1:1000, AKT 1:1000, p-AKT 1:1000, p-mTOR 1:1000, mTOR 1:1000, MMP2 1:1000, MMP9 1:500, cyclin D1 1:1000, P21 1:2000, $\mathrm{Bcl} 2$ 1:300, Bax 1:300, and GAPDH 1:1500). Bands were detected with a Western blotting analysis system.

Statistical analysis. All data were analyzed with SPSS 20.0 statistical software and the results are expressed as the mean \pm standard deviation (SD). p-values $<0.05$ and $<0.01$ were considered statistically significant. Each experiment was repeated at least three times. 


\section{Results}

FBLN3 expression in five CRC cell lines. To determine whether CRC cell lines have low levels of FBLN3 expression, we measured FBLN3 mRNA and protein levels in normal colorectal cell line FHC and colorectal cancer cell lines LOVO, SW620, SW1116, SW480, and HCT116 using RT-PCR and western blotting. FBLN3 expression was the lowest in SW480 cells (Figure 1).

FBLN3 overexpression via lentivirus vectors infection. After SW480 cells were cultured in six-well plates for $24 \mathrm{~h}$, the cells were divided into three groups: 1) control, treated with
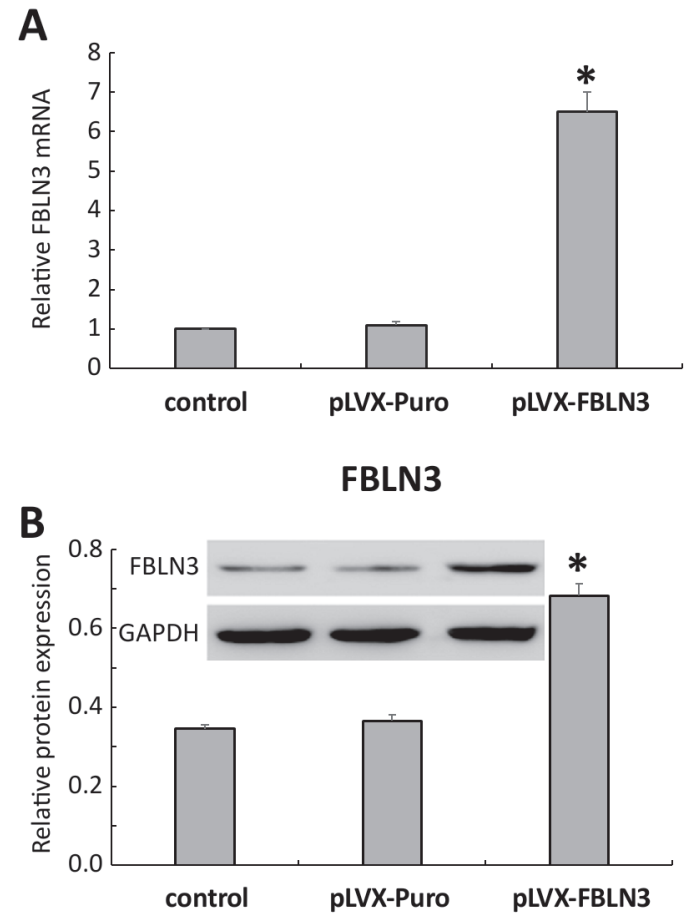

Figure 2. A) FBLN3 mRNA levels increased in SW480 cells after transfection. B) FBLN3 protein levels increased in SW480 cells after transfection $\left({ }^{*} \mathrm{p}<0.001\right)$.

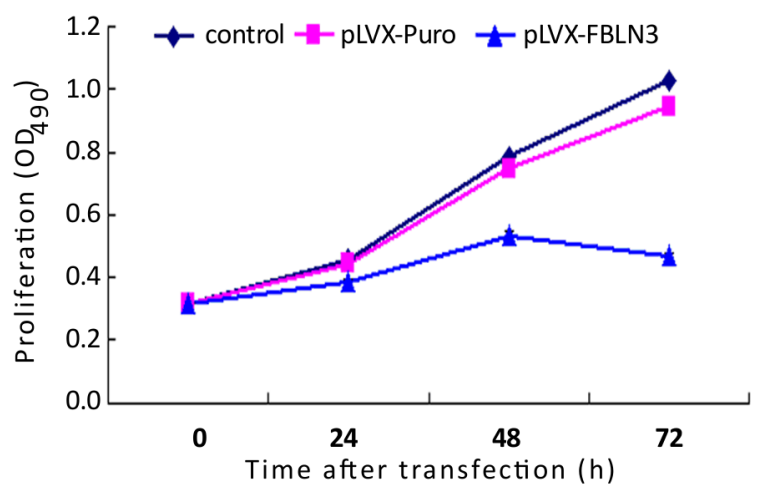

Figure 3. Proliferation of SW480 cells at different times after transfection. Compared with the control and pLVX-puro groups, the FBLN3 overexpression group presented significantly inhibited cell proliferation $(\mathbf{p}<0.01)$.
$2 \mathrm{ml}$ of medium; 2) pLVX-puro, treated with $2 \mathrm{ml}$ of medium containing $10 \mu \mathrm{l}$ of NC lentivirus; and 3) pLVX-FBLN3, treated with $2 \mathrm{ml}$ of medium containing $10 \mu \mathrm{l}$ of lentivirus overexpressing FBLN3; the FBLN3 target sequence used is mentioned in the Materials and methods section. According to the results of RT-PCR and western blotting, FBLN3 levels were markedly higher in the pLVX-FBLN3 group than in the other two groups after $48 \mathrm{~h}$, confirming successful infection (Figure 2).

FBLN3 overexpression inhibits SW480 cell proliferation. MTT assay was employed to determine cell proliferation ability after transfection. The OD490 values of FBLN3-

A
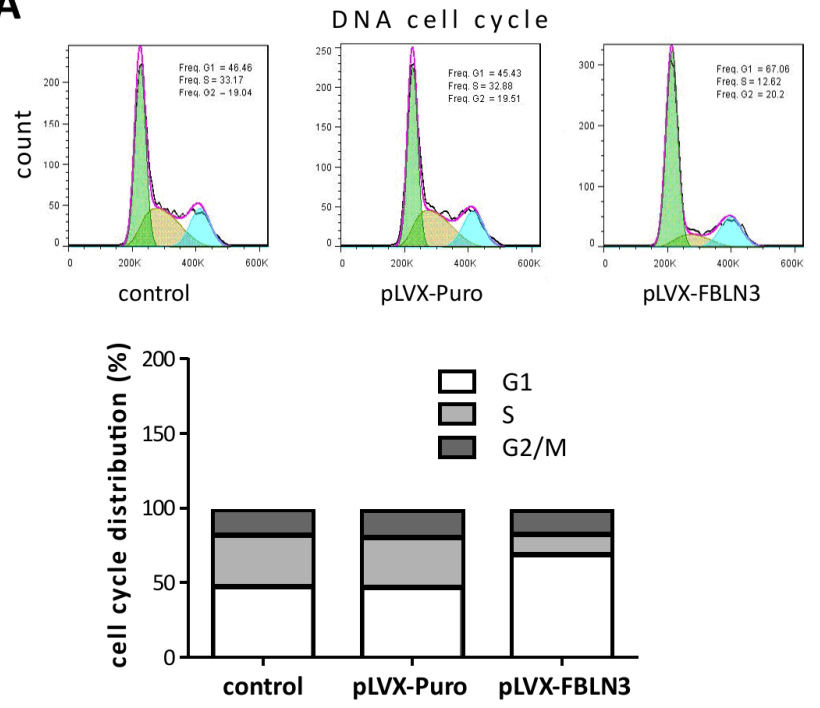

$B$
$\frac{1}{0}$
$\frac{0}{0}$
0
$\frac{0}{\varepsilon}$
$\frac{1}{2}$
$\frac{0}{0}$
$\frac{0}{2}$
$\frac{0}{2}$
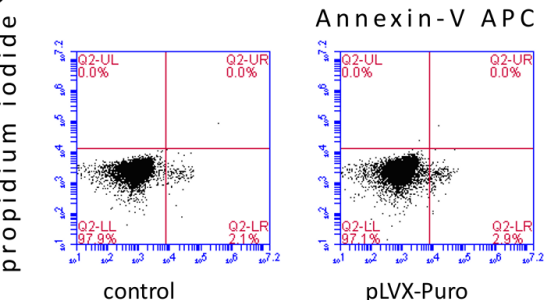

pLVX-Puro

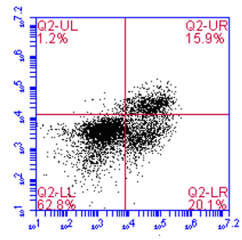

pLVX-FBLN3

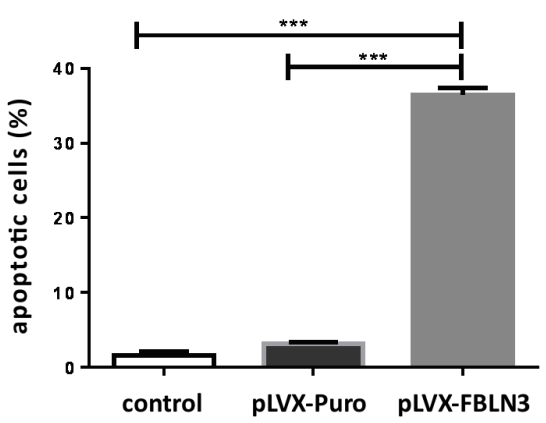

Figure 4. A) Cell cycle analysis via flow cytometry. Compared with the control and pLVX-puro groups, the FBLN3 overexpression group exhibited G1/S arrest. B) Apoptosis analysis via flow cytometry. Compared with the control and pLVX-puro groups, the FBLN3 overexpression group showed increased apoptosis $\left({ }^{* *} \mathrm{p}<0.0001\right)$. 
overexpressing cells decreased gradually compared to those of the control and negative groups. The differences were increasingly clear over time and reached statistical significance $(\mathrm{p}<0.001$, Table 1 , Figure 3$)$.

FBLN3 overexpression alters cell cycle populations and promotes apoptosis. Cell cycle percentages and apoptosis were detected by flow cytometry analyses. According to the results, the percentage of cells was increased in G1 phase and decreased in S phase in SW480 cells overexpressing FBLN3 (Figure 4A). These results indicate that the G1/S cell cycle transition was inhibited and that apoptosis was promoted (Figure 4B). Taken together, the results suggest that FBLN3 overexpression had antitumor effects.

Cell invasion and migration assays. To further investigate the inhibitory effects of FBLN3 overexpression, we used transwell assays to determine cell invasion and migration. As shown in Figure 5A and 5B, the average counts of invading and migrating cells were notably lower in the FBLN3 overexpression group than in the control and pLVX-puro groups after $48 \mathrm{~h}$ transfection. Thus, cell invasion and migration were inhibited.

Protein expression levels of AKT/mTOR pathwayrelated targets. It is well known that the $\mathrm{PI} 3 \mathrm{~K} / \mathrm{Akt} / \mathrm{mTOR}$ pathway has a vital role in modulating cell cycle, apoptosis, proliferation, and autophagy. In many cancers, this pathway is overactive to reduce apoptosis and permit proliferation. We had found that FBLN3 was downregulated in patients with colorectal cancer, and its overexpression could promote apoptosis and inhibit proliferation. But whether it is related to the $\mathrm{AKT} / \mathrm{mTOR}$ pathway activation remains

\section{A}
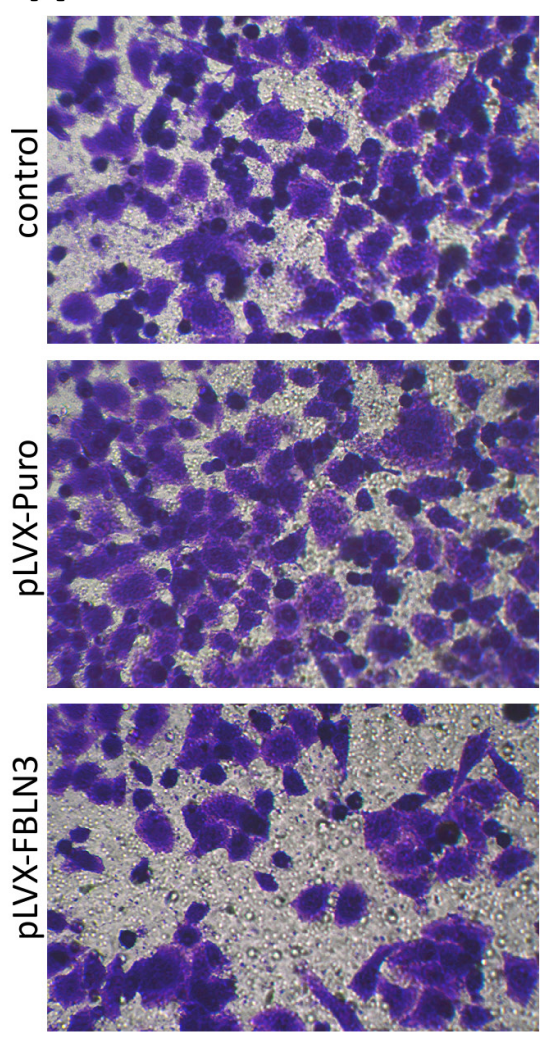

Invasion

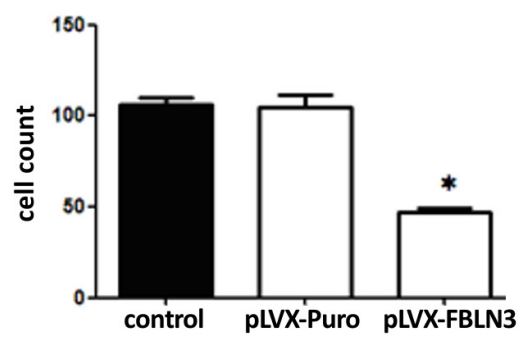

B
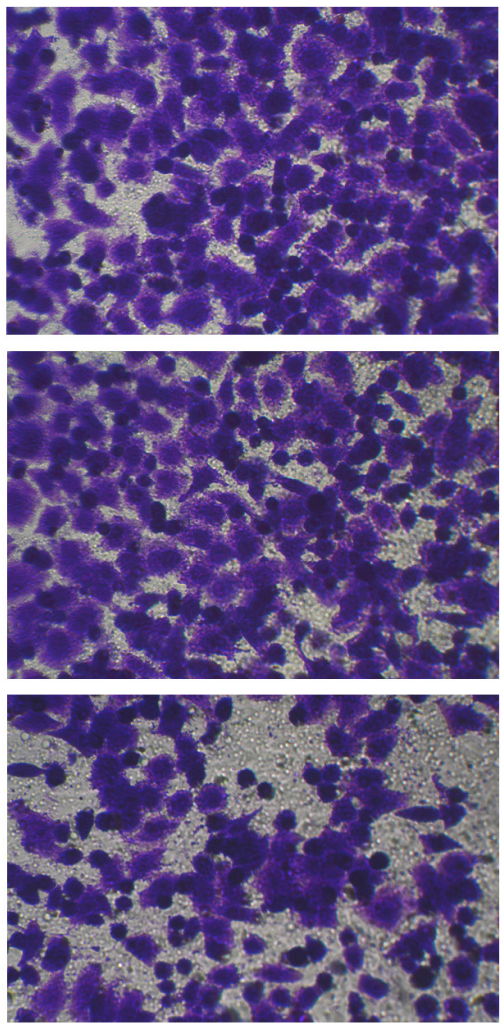

Migration

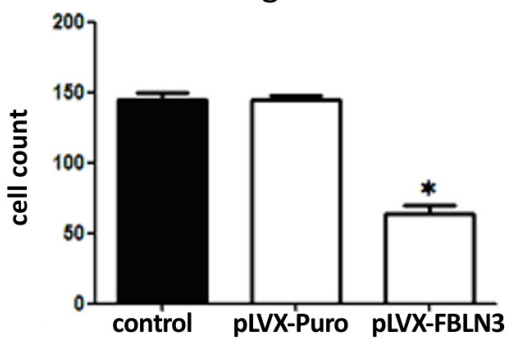

Figure 5. A) Compared with the control and pLVX-puro groups, the FBLN3 overexpression group displayed reduced cell invasion $\left({ }^{*} \mathrm{p}<0.01\right)$. B) Compared with the control and pLVX-puro groups, the FBLN3 overexpression group had decreased cell migration $\left({ }^{*} \mathrm{p}<0.01\right)$. 
unclear. Thus, we performed western blotting and found that FBLN3 overexpression significantly downregulated p-AKT, p-mTOR, MMP-2, MMP-9, Bcl-2 and Cyclin D1 and significantly enhanced Bax and P21 expression. These results explain why FBLN3 overexpression inhibited migration and invasion of CRC (Figure 6).

\section{Discussion}

Many oncogenes, anti-oncogenes and pathways participate in the tumorigenesis process and metastasis. FBLN3, which is also called epidermal growth factor-containing fibulin-like extracellular matrix protein 1 (EFEMP1), is related to many diseases, such as age-related macular degeneration [7], knee osteoarthritis [8], asbestos-related diseases [9], rheumatoid arthritis [10], mesothelioma [11], glioblastoma [12], osteosarcoma [13], ovarian cancer [14] and cervical cancer [15]. Many studies have reported that the fibulin family, which consists of 7 secreted extracellular glycoproteins, is involved in cell morphology maintenance, cell growth, adhesion and movement. FBLN3 of the fibulin family is widely expressed in blood vessel walls and exhibits both tumor suppressive and oncogenic activities. Expression of FBLN3 varies among different cancer tissue types. In ovarian cancer [14], cervical cancer [15], pancreatic adenocarcinoma [16] and malignant gliomas [17], FBLN3 is upregulated and correlates with advanced tumor stage and lymph node metastasis. In contrast, FBLN3 is downregulated in hepatocellular carcinoma $[18,19]$, gastric cancer [20], lung cancer [21, 22], endometrial carcinoma [23] and nasopharyngeal carcinoma [24]. The reasons for these differences remain unclear. In our previous research, we found that FBLN3 expression was downregulated in CRC tissues and that this downregulation played an important role in metastasis and poor survival. Thus, FBLN3 may be considered a prognostic indicator [25]. Overall, the results indicate that FBLN3 may act as an anti-oncogene in CRC. FBLN3 can also have anti-cancer effects and be a therapeutic target in malignant tumors [26, 27].

In the present study, we aimed to determine whether FBLN3 overexpression inhibits migration and invasion of CRC cells as well as the potential mechanisms. After transfection of SW480 cells with a lentivirus overexpressing FBLN3 RNA for $48 \mathrm{~h}$, we found that cell proliferation was attenuated, apoptosis was promoted and G1/S cell cycle arrest was induced. FBLN3 upregulation also inhibited cell migration and invasion. These data indicate that FBLN3 overexpression may control the CRC cell growth, acting as an anti-oncogene in CRC. This conclusion is similar to that in our previous study. However, the underlying mechanism remains unclear.

CRC development is caused by migration and invasion that occurs in cancer cells. Many pathological steps, including signaling pathway activation, participate in this process. As shown in previous reports, FBLN3 has been correlated with
Table 1. Time-dependent effect of FBLN3 expression on cell proliferation.

\begin{tabular}{lccccc}
\hline Time & Control & pLVX-puro & pLVX-FBLN3 & F & p-value \\
\hline $24 \mathrm{~h}$ & $0.460 \pm 0.011$ & $0.445 \pm 0.009$ & $0.386 \pm 0.008$ & 55.999 & $<0.001$ \\
$48 \mathrm{~h}$ & $0.787 \pm 0.009$ & $0.750 \pm 0.004$ & $0.535 \pm 0.011$ & 785.804 & $<0.001$ \\
$72 \mathrm{~h}$ & $1.031 \pm 0.005$ & $0.949 \pm 0.014$ & $0.467 \pm 0.012$ & 2304.702 & $<0.001$ \\
\hline
\end{tabular}
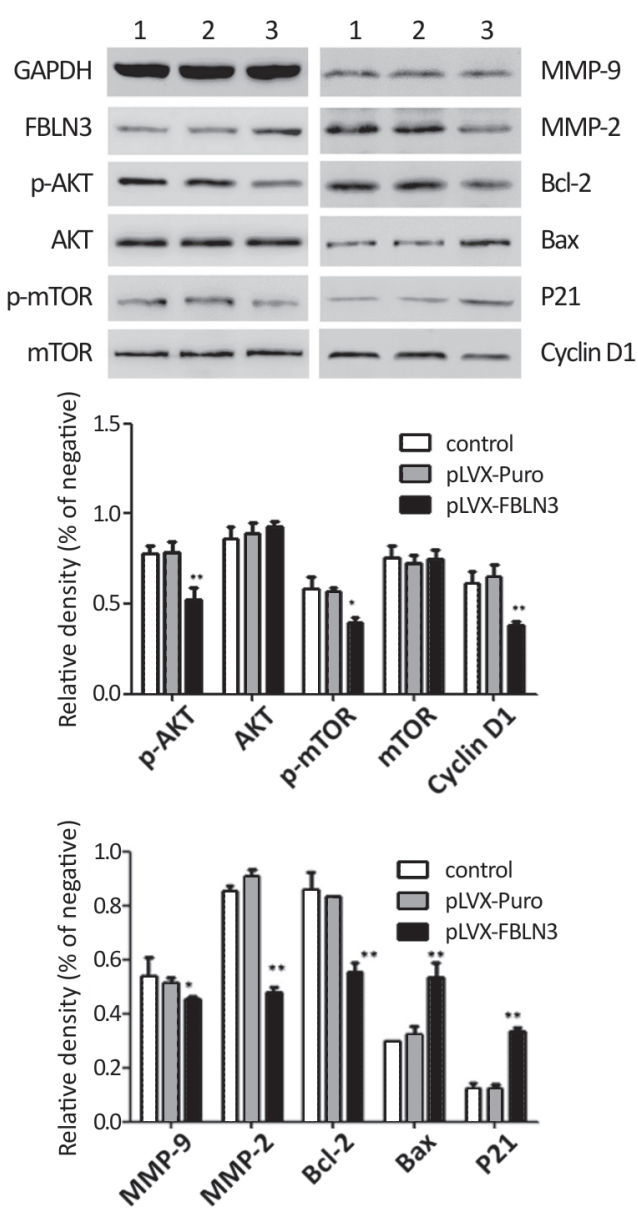

Figure 6. Expression of AKT/mTOR-related targets, as determined by western blotting. 1 - control, 2 - pLVX-puro and 3 - FBLN3 overexpression group $\left({ }^{*} \mathrm{p}<0.01,{ }^{* *} \mathrm{p}<0.001\right)$.

many pathways, including Wnt $/ \beta$-catenin and NF/kB. PI3K/ $\mathrm{AKT} / \mathrm{mTOR}$, which is one of the most commonly mutated pathways in tumors [28], is critical in CRC. Moreover, upstream and downstream targets of the PI3K/AKT/mTOR pathway are involved not only in regulating cell metabolism, proliferation, cell cycle and apoptosis, but also in the cancer development and metastasis and chemoresistance [29]. Evidence shows that activation status of this pathway is associated with response to the platinum-based chemotherapy treatment in several cancers [30-32].

AKT is an important downstream molecule of PI3K, and mTOR is the pivotal substrate of AKT. It has been reported 
that over-phosphorylation of AKT is associated with chemoresistance [33]. AKT over-phosphorylation may also activate many downstream targets in the cytoplasm and nucleus to induce cell growth. mTOR activation can promote eukaryotic initiation factor 4E (4EBP1) and result in cell proliferation. In the present study, cell proliferation was reduced by FBLN3 overexpression.

Cell death is controlled by apoptosis, an important physiological process. Most apoptosis-inducing factors eventually cause cell death through the caspase family [34]. In the $\mathrm{PI} 3 \mathrm{~K} / \mathrm{AKT} / \mathrm{mTOR}$ pathway, $\mathrm{Bcl}-2$ and $\mathrm{Bax}$, the two main opposing proteins, induce apoptosis and tumorigenesis. $\mathrm{Bcl}-2$ functions as an anti-apoptosis protein, whereas Bax acts as a pro-apoptosis protein. Members of the Bcl-2 family critically regulate mitochondrial outer membrane permeabilization (MOMP), a point-of-no-return in the intrinsic and extrinsic apoptosis pathways. Bax can induce release of cytochrome $\mathrm{c}$ from the mitochondrial membrane, which can form a heterodimer with $\mathrm{Bcl}-2$. The relative expression levels of these two factors determine cell survival.

Cell growth is also related to the cell cycle. Cyclin D1, a G1/S-specific cyclin encoded by CCND1, functions as a regulator of cyclin-dependent kinases (CDKs). Cyclin D1 is overexpressed in many cancers and its upregulation can drive proliferation. Cyclin D1 conjugates with and activates CDK4 to phosphorylate the retinoblastoma gene $(\mathrm{Rb})$, which disaggregates from E2F to promote G1 to S phase transition. Cyclin D1 upregulation also positively regulates G1/S cell cycle progression. P21 is an important member of the cyclin-dependent kinase inhibitor family which is associated with cell cycle progression and tumor inhibition [35]. In our study, we found that FBLN3 overexpression induced G1/S arrest by decreasing cyclin D1 expression and increasing P21 expression. Therefore, deregulation of the PI3K/AKT/mTOR pathway induces apoptosis and G1/S arrest and alters energy and substance metabolism [36].

MMPs are considered to have a role in cell proliferation, adhesion, migration and metastasis [37]. Type IV collagen is an important component of the extracellular matrix, and MMPs can reduce its expression. Many experts have studied MMP-2 and MMP-9, which can degrade and remold the dynamic balance of the extracellular matrix. Downregulating these two proteins inhibits NSCLC migration, invasion and metastasis. In the present study, we found that MMP-2 and MMP-9 levels were reduced, inhibiting CRC migration, invasion and metastasis.

In conclusion, FBLN3 can act as an anti-oncogene. FBLN3 overexpression obviously inhibited growth, invasion and metastasis of the CRC cells through the AKT/mTOR pathway. FBLN3 is thought to be a potential target for the prognosis and treatment of CRC and can be widely applied in clinical practice.

Acknowledgments: This research was supported by the project of YangZhou Science and Technology Burean (YZ2018071).

\section{References}

[1] SIEGEL RL, MILLER KD, JEMAL A. Cancer statistics, 2017. CA Cancer J Clin 2017; 67: 7-30. https://doi.org/10.3322/ caac. 21387

[2] CHEN W, ZHENG R, BAADE PD, ZHANG S, ZENG H et al. Cancer statistics in China, 2015. CA Cancer J Clin 2016; 66: 115-132. https://doi.org/10.3322/caac.21338

[3] WANG L, WILSON SE, STEWART DB, HOLLENBEAK CS. Marital status and colon cancer outcomes in US Surveillance, Epidemiology and End Results registries: does marriage affect cancer survival by gender and stage? Cancer Epidemiol 2011; 35: 417-422. https://doi.org/10.1016/j. canep.2011.02.004

[4] SARMA EA, KAWACHI I, POOLE EM, TWOROGER SS, GIOVANNUCCI EL et al. Social integration and survival after diagnosis of colorectal cancer. Cancer 2018; 124: 833840. https://doi.org/10.1002/cncr.31117

[5] OKIMOTO RA, BREITENBUECHER F, OLIVAS VR, WU $\mathrm{W}$, GINI B et al. Inactivation of Capicua drives cancer metastasis. Nat Genet 2017; 49: 87-96. https://doi.org/10.1038/ ng. 3728

[6] DE VEGA S, IWAMOTO T, YAMADA Y. Fibulins: multiple roles in matrix structures and tissue functions. Cell Mol Life Sci 2009; 66: 1890-1902. https://doi.org/10.1007/s00018009-8632-6

[7] RAJAPAKSE D, PETERSON K, MISHRA S, WISTOW G. Serum starvation of ARPE-19 changes the cellular distribution of cholesterol and Fibulin3 in patterns reminiscent of age-related macular degeneration. Exp Cell Res 2017; 361: 333-341. https://doi.org/10.1016/j.yexcr.2017.10.036

[8] WU Q, SUN X, DU L. Association of fibulin-3 concentrations with the presence and severity of knee osteoarthritis: A cross-sectional study. Knee 2017; 24: 1369-1373. https://doi. org/10.1016/j.knee.2017.04.018

[9] JIANG Z, YING S, SHEN W, HE X, CHEN J et al. Plasma Fibulin-3 as a Potential Biomarker for Patients with Asbestos-Related Diseases in the Han Population. Dis Markers 2017; 2017: 1725354. https://doi.org/10.1155/2017/1725354

[10] KOPEC-MEDREK M, KUCHARZ EJ. Fibulin-3 and other cartilage metabolism biomarkers in relationship to calprotectin (MRP8/14) and disease activity in rheumatoid arthritis patients treated with anti-TNF therapy. Adv Clin Exp Med 2018; 27: 383-389. https://doi.org/10.17219/ acem $/ 68362$

[11] SUN HH, VAYNBLAT A, PASS HI. Diagnosis and prognosis-review of biomarkers for mesothelioma. Ann Transl Med 2017; 5: 244. https://doi.org/10.21037/atm.2017.06.60

[12] NANDHU MS, BEHERA P, BHASKARAN V, LONGO SL, BARRERA-ARENAS LM et al. Development of a FunctionBlocking Antibody Against Fibulin-3 as a Targeted Reagent for Glioblastoma. Clin Cancer Res 2018; 24: 821-833. https:// doi.org/10.1158/1078-0432.CCR-17-1628

[13] WANG S, ZHANG D, HAN S, GAO P, LIU C et al. Fibulin-3 promotes osteosarcoma invasion and metastasis by inducing epithelial to mesenchymal transition and activating the Wnt/ $\beta$ - catenin signaling pathway. Sci Rep 2017; 7: 6215-6231. https://doi.org/10.1038/s41598-017-06353-2 
[14] YIN X, FANG S, WANG M, WANG Q, FANG R et al. EFEMP1 promotes ovarian cancer cell growth, invasion and metastasis via activated the AKT pathway. Oncotarget 2016; 7: 47938-47953.

[15] SONG EL, HOU YP, YU SP, CHEN SG, HUANG JT et al. EFEMP1 expression promotes angiogenesis and accelerates the growth of cervical cancer in vivo. Gynecol Oncol 2011; 121: 174-180. https://doi.org/10.1016/j.ygyno.2010.11.004

[16] SEELIGER H, CAMAJ P, ISCHENKO I, KLEESPIES A, DE TONI EN et al. EFEMP1 expression promotes in vivo tumor growth in human pancreatic adenocarcinoma. Mol Cancer Res 2009; 7: 189-198. https://doi.org/10.1158/1541-7786. MCR-08-0132

[17] HU B, THIRTAMARA-RAJAMANI KK, SIM H, VIAPIANO MS. Fibulin-3 is uniquely upregulated in malignant gliomas and promotes tumor cell motility and invasion. Mol Cancer Res 2009; 7: 1756-1770. https://doi. org/10.1158/1541-7786.MCR-09-0207

[18] DOU CY, CAO CJ, WANG Z, ZHANG RH, HUANG LL et al. EFEMP1 inhibits migration of hepatocellular carcinoma by regulating MMP2 and MMP9 via ERK1/2 activity. Oncol Rep 2016; 35: 3489-3495. https://doi.org/10.3892/ or.2016.4733

[19] LUO R, ZHANG M, LIU L, LU S, ZHANG CZ et al. Decrease of fibulin-3 in hepatocellular carcinoma indicates poor prognosis. PLoS One 2013; 8: e70511. https://doi. org/10.1371/journal.pone.0070511

[20] ZHU XJ, LIU J, XU XY, ZHANG CD, DAI DQ. Novel tumor-suppressor gene epidermal growth factor-containing bulin-like extracellular matrix protein 1 is epigenetically silenced and associated with invasion and metastasis in human gastric cancer. Mol Med Rep 2014; 9: 2283-2292. https://doi. org $/ 10.3892 / \mathrm{mmr} .2014 .2135$

[21] CHEN X, MENG J, YUE W, YU J, YANG J et al. Fibulin-3 suppresses $\mathrm{Wnt} / \beta$-catenin signaling and lung cancer invasion. Carcinogenesis 2014; 35: 1707-1716. https://doi. org/10.1093/carcin/bgu023

[22] KIM IG, KIM SY, CHOI SI, LEE JH, KIM KC et al. Fibulin3-mediated inhibition of epithelial-to-mesenchymal transition and self-renewal of ALDH+ lung cancer stem cells through IGF1R signaling. Oncogene 2014; 33: 3908-3917. https://doi.org/10.1038/onc.2013.373

[23] YANG T, QIU H, BAO W, LI B, LU C et al. Epigenetic inactivation of EFEMP1 is associated with tumor suppressive function in endometrial carcinoma. PLoS One 2013; 8: e67458. https://doi.org/10.1371/journal.pone.0067458

[24] HWANG CF, CHIEN CY, HUANG SC, YIN YF, HUANG $\mathrm{CC}$ et al. Fibulin-3 is associated with tumour progression and a poor prognosis in nasopharyngeal carcinomas and inhibits cell migration and invasion via suppressed AKT activity. J Pathol 2010;222:367-379. https://doi.org/10.1002/path.2776

[25] TONG JD, JIAO NL, WANG YX, ZHANG YW, HAN F. Downregulation of fibulin-3 gene by promoter methylation in colorectal cancer predicts adverse prognosis. Neoplasma 2011; 58: 441-448. https://doi.org/10.4149/ neo_2011_05_441
[26] LI Y, HU Y, LIU C, WANG Q, HAN X et al. Human bulin-3 protein variant expresses anti-cancer effects in the malignant glioma extracellular compartment in intracranial xenograft models. Oncotarget 2017; 8: 106311-106323. https://doi. org/10.18632/oncotarget.22344

[27] NANDHU MS, BEHERA P, BHASKARAN V, LONGO SL, BARRERA-ARENAS LM et al. Development of a functionblocking antibody against fibulin-3 as targeted reagent for glioblastoma. Clin Cancer Res 2018; 24: 821-833. https://doi. org/10.1158/1078-0432.CCR-17-1628

[28] BRUHN MA, PEARSON RB, HANNAN RD, SHEPPARD KE. AKT-independent PI3-K signaling in cancer emerging role for SGK3. Cancer Manag Res 2013; 5: 281-292. https:// doi.org/10.2147/CMAR.S35178

[29] LV X, LI CY, HAN P, XU XY. MicroRNA-520a-3p inhibits cell growth and metastasis of non-small cell lung cancer through PI3K/AKT/mTOR signaling pathway. Eur Rev Med Pharmacol Sci 2018; 22: 2321-2327. https://doi. org/10.26355/eurrev_201804_14822

[30] XU JL, WANG ZW, HU LM, YIN ZQ, HUANG MD et al. Genetic variants in the PI3K/PTEN/AKT/mTOR pathway predict platinum-based chemotherapy response of advanced non-small cell lung cancers in a Chinese population. Asian Pac J Cancer Prev 2012; 13: 2157-2162.

[31] PENG DJ, WANG J, ZHOU JY, WU GS. Role of the Akt/ mTOR survival pathway in cisplatin resistance in ovarian cancer cells. Biochem Biophys Res Commun 2010; 394: 600605. https://doi.org/10.1016/j.bbrc.2010.03.029

[32] XIU P, DONG X, DONG X, XU Z, ZHU H et al. Secretory clusterin contributes to oxaliplatin resistance by activating Akt pathway in hepatocellular carcinoma. Cancer Sci 2013; 104: 375-382. https://doi.org/10.1111/cas.12088

[33] SARRIS EG, SAIF MW, SYRIGOS KN. The biological role of PI3K pathway in lung cancer. Pharmaceuticals (Basel) 2012; 5: 1236-1264. https://doi.org/10.3390/ph5111236

[34] TIAN Z, WANG J, XU M, WANG Y, ZHANG $M$ et al. Resveratrol Improves Cognitive Impairment by Regulating Apoptosis and Synaptic Plasticity in Streptozotocin-Induced Diabetic Rats. Cell Physiol Biochem 2016; 40: 1670-1677. https://doi.org/10.1159/000453216

[35] LI Y, HUANG J, ZENG B, YANG D, SUN J et al. PSMD2 regulates breast cancer cell proliferation and cell cycle progression by modulating $\mathrm{p} 21$ and $\mathrm{p} 27$ proteasomal degradation. Cancer Lett 2018; 430: 109-122. https://doi.org/10.1016/j. canlet.2018.05.018

[36] PENG Y, QIU L, XU D, ZHANG L, YU H et al. M4IDP, a zoledronic acid derivative, induces $\mathrm{G} 1$ arrest, apoptosis and autophagy in HCT116 colon carcinoma cells via blocking PI3K/Akt/mTOR pathway. Life Sci 2017; 185: 63-72. https:// doi.org/10.1016/j.lfs.2017.07.024

[37] TAKI M, VERSCHUEREN K, YOKOYAMA K, NAGAYAMA M, KAMATA N. Involvement of Ets-1 transcription factor in inducing matrix metalloproteinase-2 expression by epithelial-mesenchymal transition in human squamous carcinoma cells. Int J Oncol 2006; 28: 487-496. https://doi. org/10.3892/ijo.28.2.487 